\title{
MUSCARINIC CHOLINERGIC RECEPTORS IN MAMMALIAN BRAIN: DIFFERENCES BETWEEN BINDINGS OF ACETYLCHOLINE AND ATROPINE
}

\author{
Shuji UCHIDA, Kunio TAKEYASU, Seiji ICHIDA \\ and Hiroshi YOSHIDA \\ Department of Pharmacology I, Osaka University School of Medicine, \\ Kita-ku, Osaka 530, Japan \\ Accepted May 10, 1978
}

\begin{abstract}
Studies were made on the bindings of $\left[{ }^{3} \mathrm{H}\right]$-acetylcholine and $\left[{ }^{3} \mathrm{H}\right]$-atropine to synaptic plasma membrancs from rat brain. Synaptic plasma membranes have reversible, high affinity binding sites for both ligands, the $\mathrm{K}_{\mathrm{D}}$ values for $\mathrm{ACh}$ and atropine being about $20 \mathrm{nM}$ and $1 \mathrm{nM}$, respectively. The maximal binding capacities for $\mathrm{ACh}$ and atropine, respectively, are $0.8-1.2$ pmoles and about 1.5 pmoles/mg protein of synaptic membranes. The specific binding of ACh is almost completely inhibited by oxotremorine and atropine.

5,5'-Dithiobis (2-nitrobenzoic acid) (DTNB) increased the ACh-binding to about $1.5 \mathrm{pmole} / \mathrm{mg}$ protein. It also increased the inhibition of atropine-binding by $\mathrm{ACh}$ about 10 -fold. Marked discrepancies were found in the inhibitions of atropine- and ACh-bindings by muscarinic agonists, but not in the inhibitions by antagonists. These findings support the hypothesis that muscarinic receptors have different sites for agonists and antagonists. The possibility that one receptor can be simultaneously occupied by both an agonist and an antagonist is also discussed.
\end{abstract}

Various muscarinic and antimuscarinic drugs act on the central nervous system and are used for therapeutic purposes. Electrophysiological studies have suggested that some of the neurons in this system are muscarinic $(1,2,3)$, and binding experiments using various muscarinic agonists and antagonists revealed the distribution of muscarinic receptors in the central nervous system $(4,5,6)$. It has also been suggested that there are presynaptic muscarinic receptors, which regulate acetylcholine ( $\mathrm{ACh}$ ) release at cholinergic synapses (7).

However, recent findings cannot be explained on the basis of classical ideas on receptors. Ariëns and coworkers suggested that in many kinds of receptors agonists and antagonists may bind to different sites on the same receptor (8). Moreover, Snyder et al. demonstrated that the inhibitory effects of muscarinic agonists on the binding of an antagonist, 3-quinuclidinyl benzilate, are weaker than their pharmacological effects (4). Rosen et al. suggested that atropine and $\mathrm{ACh}$ may bind to adjacent or overlapping sites rather than to the same site on receptors in guinea pig ileum (9).

This paper describes differences in the bindings of $\mathrm{ACh}$ and atropine to synaptic plasma membranes from rat brain.

\section{MATERIALS AND METHODS}

$\left[{ }^{3} \mathrm{H}\right]$-Atropine sulfate $(880 \mathrm{mCi} / \mathrm{mmole})$, acetyl[ $\mathrm{N}$-methyl $\left.{ }^{3} \mathrm{H}\right]$ choline cholride $(200$ 
$\mathrm{mCi} /$ mmole) and ${ }^{3} \mathrm{H}$-quinuclidinyl benzilate (29.4 Ci/mmole) were obtained from Institut National des Radioelements, Belgium, the Radiochemical Centre, Amersham and New England Nuclear, respectively.

\section{Preparation of synaptic plasma membranes}

Sprague-Dawley rats weighing 200-300 g were used. Synaptic plasma membranes were prepared from the brains (after removal of the cerebellum and pons) by the method of Whittaker et al. (10) with slight modifications (11). The synaptic plasma membranes were then suspended in $20 \mathrm{mM}$ Tris- $\mathrm{HCl}$ buffer $(\mathrm{pH} \mathrm{7.4)}$ and stored at $-80 \mathrm{C}$ until use. All experiments were carried out within 10 days after isolating the membranes.

\section{Binding assay}

Synaptic plasma membranes, which had been stored at $-80^{\circ} \mathrm{C}$, were sonicated for $1 \mathrm{~min}$ (in a Kontes sonicator, operating at full power) to facilitate the subsequent filtration step. Experiments on the bindings of $\left[{ }^{3} \mathrm{H}\right]$-atropine and $\left[{ }^{3} \mathrm{H}\right]$ - $\mathrm{ACh}$ were performed for 1 hour at $0^{\circ} \mathrm{C}$ in mixture (3 $\mathrm{ml}$ for atropine-binding or $2 \mathrm{ml}$ for ACh-binding) containing $100 \mathrm{mM}$ $\mathrm{NaCl}, 50 \mathrm{mM}$ Tris- $\mathrm{HCl}(\mathrm{pH} 7.4), 1 \mathrm{~m} \mathrm{M} \mathrm{CaCl}$ and approximately $300 \%$ protein of synaptic plasma membranes unless otherwise indicated. The mixtures were then filtered through a membrane filter (pore size $0.45 \mu, 13 \mathrm{~mm} \phi$ Millipore or Toyo-Roshi), under vacuum. The filter was not washed to avoid dissociation during washing procedure. The radioactivities trapped on the filters were measured in Bray's solution in a liquid scintillation counter (Alokit LSC-651). Each sample was counted for 40 to $60 \mathrm{~min}$. All cpm values were converted to molar contents by use of counting efficiencies and specific radioactivities. The amounts of nonspecific bindings of the two ligands were estimated in a mixture containing 1,000 to 10,000-fold more of the unlabeled species of ligand, and the specific bindings were calculated by subtracting the nonspecific bindings from the total bindings.

\section{Determination of specific radioactivitie's}

In this paper, the specific radioactivities of atropine and ACh have an important significance because the amounts of the bindings were calculated by use of those values. The binding of ${ }^{3} \mathrm{H}$-atropine was compared with that of ${ }^{3} \mathrm{H}$-quinuclidinyl benzilate. The amounts of maximal specific bindings of both antagonists were the same. Thus we considered the data of specific activity correct. The specific radioactivity of $\mathrm{ACh}$ was calculated from the concentration determined by bioassay (the contraction of frog abdominal muscle) and the radioactivity of $\mathrm{ACh}$ separated from choline by high voltage electrophoresis (12). The calculated value agreed with the supplied value. However, $87 \%$ of total radioactivity was ${ }^{3} \mathrm{H}-\mathrm{ACh}$ at the end of the experiments for this report, one year after the purchase. We may have overestimated the $\mathrm{K}_{1}$, value of $\mathrm{ACh}$-binding but not so the maximal bindings as the amounts of maximal binding were determined by specific radioactivity. Therefore, this fact will have no essential effect on following discussions.

\section{RESULTS}

Characteristics of ACh-and atropine-bindings to synaptic plasma membranes

The bindings of the two ligands were completely reversible and reached quilibrium 
within $40 \mathrm{~min}$ at $0^{\circ} \mathrm{C}$ and the maximum amounts of atropine-bindings on incubation at $37^{\circ} \mathrm{C}, 20^{\circ} \mathrm{C}$ and $0^{\circ} \mathrm{C}$ were similar. Therefore, in binding experiments incubations were carried out for 1 hour at $0^{\circ} \mathrm{C}$ to minimize the hydrolysis of the ligands. We examined the hydrolysis of $\mathrm{ACh}$ under this condition at which $10^{-5} \mathrm{M}$ eserine was present. The hydrolysis of ACh during the incubation was less than $10 \%$ measured by high voltage electrophoresis. In this paper the word 'binding' indicates specific bindings, as described under Materials and Methods, unless otherwise noted. We defined the saturable bindings as specific bindings, a word used widely, for these bindings have high affinity and were specific for muscarinic drugs as shown in following results and discussions.

Fig. 1 shows results on the binding of $\left[{ }^{3} \mathrm{H}\right]-\mathrm{ACh}$ and a double reciprocal plot of the values. The ratio of specific binding to total binding was about $30 \%$ at half maximal concentration. Fig. 2 shows results on atropine-binding. The specific binding of atropine was about $70 \%$ of the total binding of atropine at half maximal concentration. The nonspecific bindings of both ligands increased linearly with their concentrations. The linearities of the double reciprocal plots for the two bindings indicate simple receptor-ligand interactions in these ranges of concentrations. However, a small fraction (less than $10 \%$ ) of the bindings with higher affinity, non-detectable in our assay ststem, may be possibly present.

The constants of the two bindings are summarized in Table 1. The maximal amount of ACh-binding was less than that of atropine-binding and varied greatly in different preparations. The affinity of atropine for binding sites was 20 times that of $\mathrm{ACh}$.

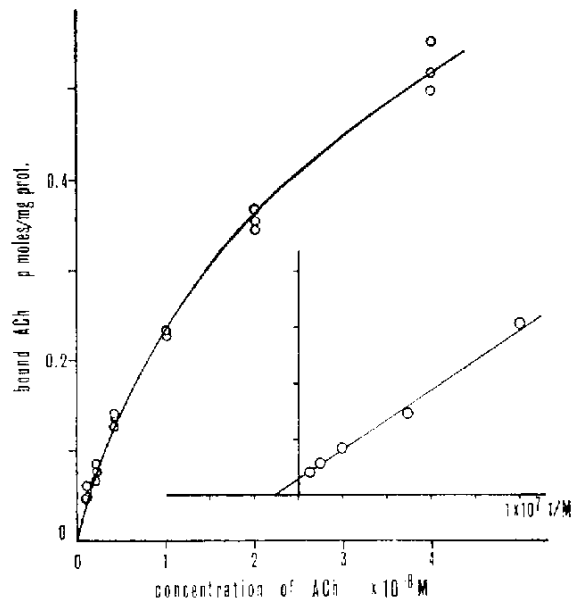

FIG. 1. ACh-binding to synaptic plasma membranes. The assay medium contained $100 \mathrm{mM} \mathrm{NaCl}, 50 \mathrm{mM}$ Tris- $\mathrm{HCl}(\mathrm{pH} \mathrm{7.4})$, $1 \mathrm{mM} \mathrm{CaCl}_{2}, 10^{-5} \mathrm{M}$ eserine and about $300 \mu \mathrm{g}$ protein of synaptic plasma membranes in a final volume of $2 \mathrm{ml}$. After incubation at $0 \mathrm{C}$ for 60 min the mixture was filtered through a membrane filter $(0.45 \mu, 13 \mathrm{~mm} \phi)$. Inset: double reciprocal plot of the binding.

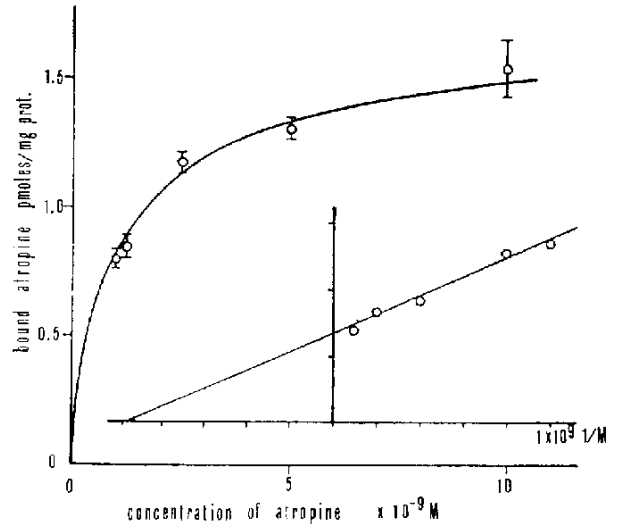

FIG. 2. Atropine-binding to synaptic plasma membranes. The experimental conditions were as for Fig. 1 except that the incubation medium did not contain eserine and the total volume was $3 \mathrm{ml}$. Vertical bars show standard deviations (S.D.). 
TABLE 1. Comparison of ACh- and atropine-binding to the synaptic membrane

\begin{tabular}{lcc}
\hline & Atropine & $\mathrm{ACh}$ \\
$\mathrm{K}_{\mathrm{D}}$ & $1 \times 10^{-4} \mathrm{M}$ & $2 \times 10^{-8} \mathrm{M}$ \\
Maximum binding & $1.5 \times 10^{-12}$ & $0.8-1.2 \times 10^{-12}$ \\
& moles $/ \mathrm{mg}$ prot. & moles $/ \mathrm{mg} \mathrm{prot.}$ \\
\hline
\end{tabular}

\section{Effects of sulfhydryl reagents on the two bindings}

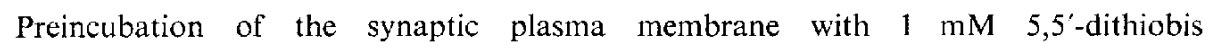
(2-nitrobenzoic acid) (DTNB) for $20 \mathrm{~min}$ at $37^{\circ} \mathrm{C}$ increased the maximal content of $\mathrm{ACh}$ binding to about $1.5 \times 10^{-12}$ moles $/ \mathrm{mg}$ protein, a value similar to that for atropine-binding (Fig. 3A). This increased binding seemed to be mainly muscarinic, because it was largely inhibited by atropine and oxotremorine (Fig. 3B, Fig. 7). The affinity for ACh was not affected by DTNB.

Neither the maximal content of atropine binding sites nor the affinity of sites for atropine was affected by DTNB (Fig. 4). However, DTNB potentiated the inhibition of atropinebinding by $\mathrm{ACh}$ about 10 times (Fig. 5). In this experiment, synaptic plasma membranes were prepared in the presence of a low concentration of dithiothreitol to make clear the difference and to minimize the deviation of control value, as the effect of DTNB varied in different preparations. In this inhibition by $\mathrm{ACh}$, the Hill number for $\mathrm{ACh}$ was 0.54 , in agreement with the observation of Birdsall and Hulme (13).

The effects of DTNB are observed even at a concentration of $0.1 \mathrm{mM}$ DTNB. Other disulfide compounds (i.e., cystine and oxidized glutathione,) and the oxidizing agent, potas-
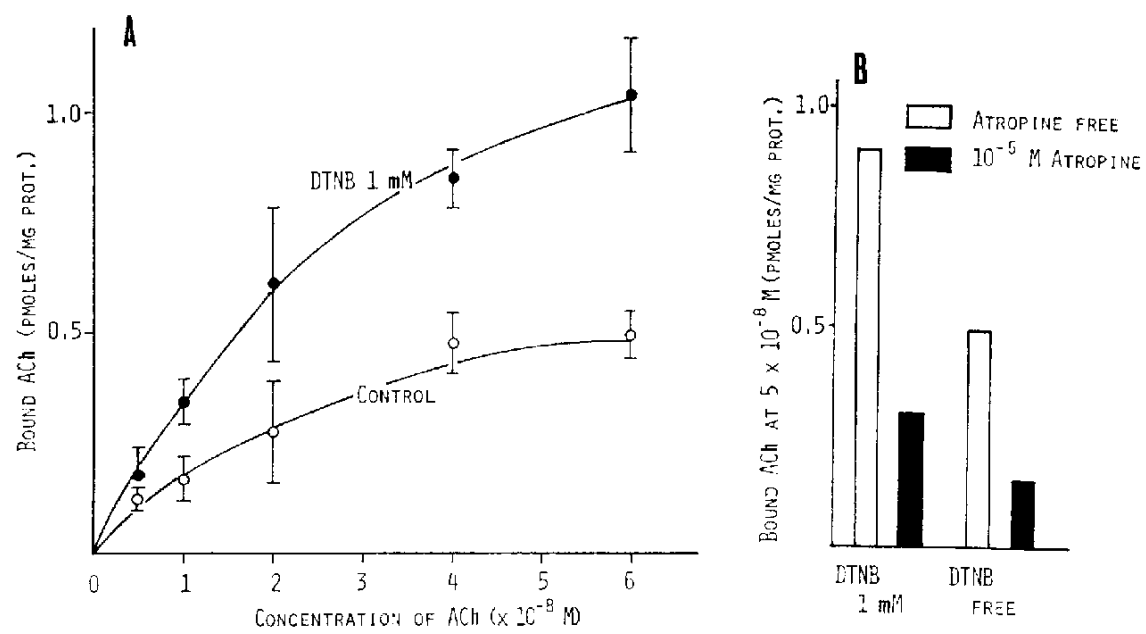

FIG. 3. Effect of DTNB on ACh-binding to synaptic plasma membranes. Synaptic plasma membranes were preineubated with $1 \mathrm{mM}$ DTNB in the same medium as for Fig. 1 at $37 \mathrm{C}$ for $20 \mathrm{~min}$. The binding of $\mathrm{ACh}$ was started by adding ${ }^{3} \mathrm{H}-\mathrm{ACh}$. Other experimental conditions were as for Fig. 1. Vertical bars show S.D. A) Binding of $\mathrm{ACh}$ for various concentrations. B) Inhibition of the binding of $\mathrm{ACh}$ by atropine. The concentrations of $\mathrm{ACh}$ and atropine were $5 \times 10^{-3} \mathrm{M}$ and $10^{-5} \mathrm{M}$ respectively. 


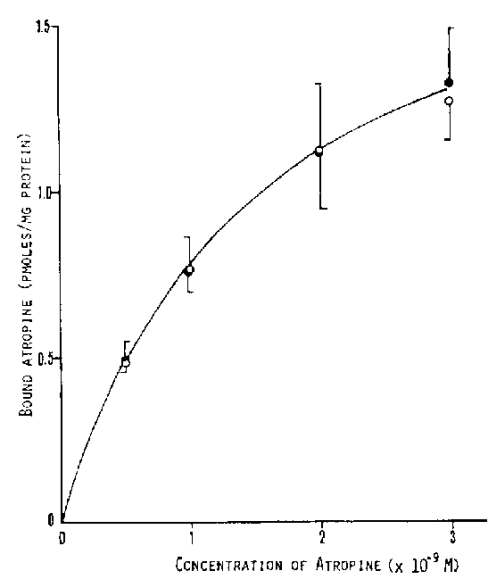

FIG. 4. Effect of DTNB on atropine-binding. The experimental conditions were as for Figs. 2 and 3. The binding of atropine was started by adding ${ }^{3} \mathrm{H}$-atropine. Open circles: Preincubated without DTNB. Filled circles: Preincubated with $1 \mathrm{mM}$ DTNB. Vertical bars show S.D.

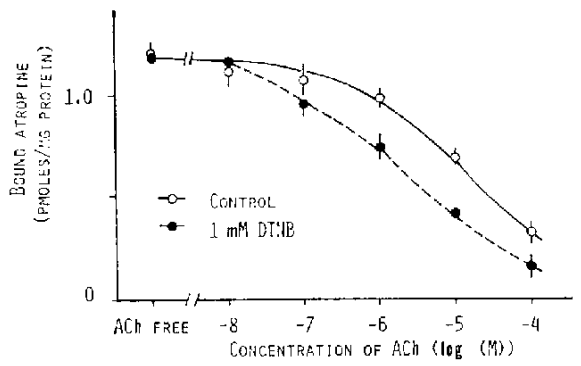

FIG. 5. Effect of DTNB on the inhibition of atropine-binding at $2 \times 10^{-9} \mathrm{M}$ by $\mathrm{ACh}$. The experimental conditions were as for Fig. 4, except that the medium contained $10^{-5} \mathrm{M}$ eserine. Synaptic plasma membranes were prepared in the presence of dithiothreitol. Vertical bars show S.D.

sium ferricyanide, had no effect on ACh-binding. p-Chloromercuribenzoic acid inhibited the bindings of both $\mathrm{ACh}$ and atropine. Dithiothreitol reduced the effect of DTNB on ACh-binding, causing $50 \%$ reduction of that observed in the presence of DTNB only.

\section{Inhibitions of the two bindings by cholinergic agents}

Fig. 6 shows the effects of agonists and antagonists on the binding of atropine $\left(2 \times 10^{-9} \mathrm{M}\right)$. The concentrations for $50 \%$ inhibition of atropine binding $\left(2 \times 10^{-8} \mathrm{M}\right)$ were approximately $2 \times 10^{-9} \mathrm{M}$ for atropine and methylatropine, $2 \times 10^{-8} \mathrm{M}$ for trihexyphenidyl, $2 \times 10^{-6} \mathrm{M}$ for oxotremorine, $1 \times 10^{-5} \mathrm{M}$ for $\mathrm{ACh}$ and $2 \times 10^{-5} \mathrm{M}$ for pilocarpine. Thus the inhibitory effects of these agonists on atropine-binding were weaker than their pharmacological actions on the peripheral nervous system (the contraction of small intestine (14) and others) and $K_{D}$ value for ACh-binding to the synaptic plasma membranes (Table 1).

In contrast, the effects of antagonists were comparable in strength to their pharmacological actions on peripheral nerves. Methylatropine had the same potency as atropine and trihexyphenidyl also strongly inhibited atropine-binding. The other cholinergic agents, d-tubocurarine, hemicholinium-3 and eserine inhibited atropine-binding slightly (less than $20 \%$ at concentrations of $10^{-5} \mathrm{M}$ ). Tremorine, which is inactive but is a precursor of oxotremorine, showed $50 \%$ inhibition at a concentration of $5 \times 10^{-5} \mathrm{M}$. This concentration is about 25 times the concentration of oxotremorine required for the same effect, but we did not test whether the tremorine we used was contaminated with oxotremorine.

Fig. 7 shows the effects of atropine and oxotremorine on ACh-binding $\left(5 \times 10^{-8} \mathrm{M}\right)$. Unlike atropine-binding, ACh-binding was inhibited by atropine and oxotremorine at concentrations comparable to those for their peripheral actions and $\mathrm{K}_{\mathrm{D}}$ for atropine-binding. 


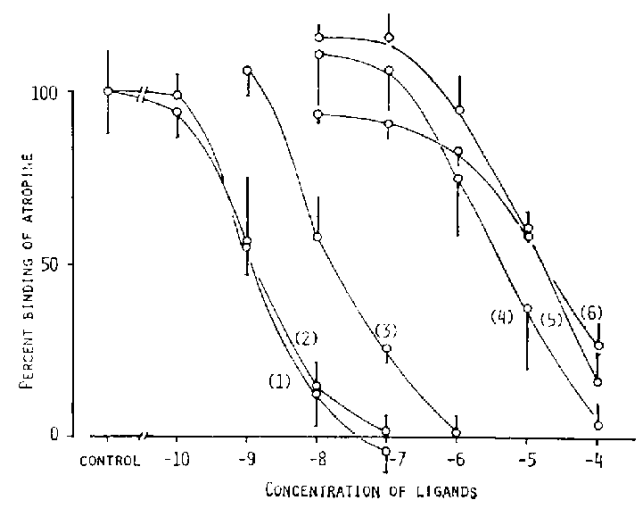

FIG. 6. Inhibition of atropine binding by cholinergic ligands. The conditions of incubation were as for Fig. 2. The concentration of atropine was $2 \times 10^{-9} \mathrm{M}$. 1) Atropine 2) Methylatropine 3) Trihexyphenidyl 4) Oxotremorine 5) ACh 6) Pilocarpine. ACh was added with $10^{-5} \mathrm{M}$ eserine. Vertical bars show S.D. Concentrations of ligands are expressed in log scale.

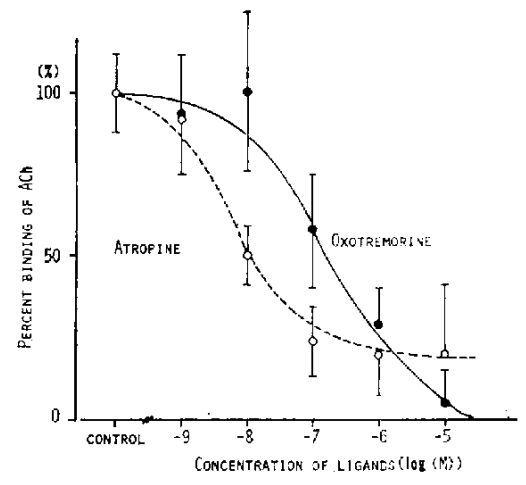

Fig. 7. Inhibition of ACh-binding at $5 \times 10^{-8}$ $M$ by atropine and oxotremorine. The conditions of incubation were as for Fig. 1. Vertical bars show S.D.

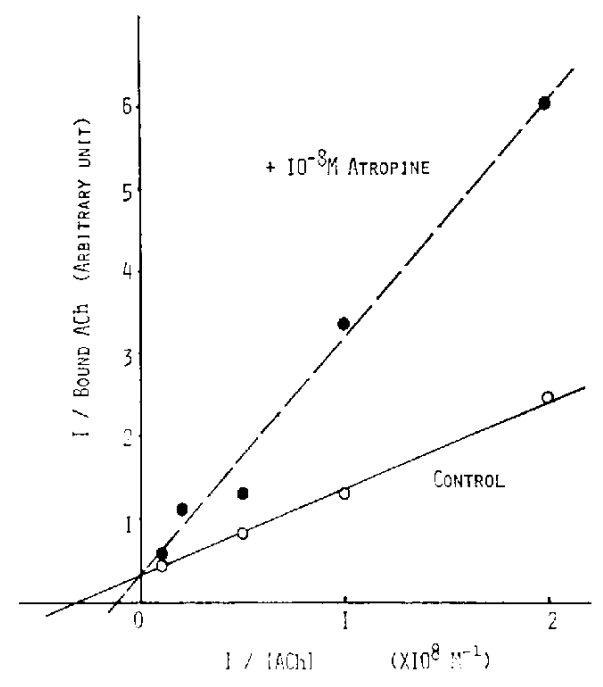

FIG. 8. Inhibition of binding of ACh by atropine. (Double reciprocal plot). Experimental conditions were as for Fig. 3. Each point shows a mean of two experiments.

There were some fractions of ACh-binding which were inhibited entirely by oxotremorine but not by atropine (Fig. 3B, Fig. 7). The inhibition by atropine was competitive, with a $\mathrm{K}_{\mathrm{I}}$ value of about $4 \times 10^{-9} \mathrm{M}$ (Fig. 8 ).

\section{DISCUSSION}

The present findings on the binding of atropine agree with those on muscarinic antagonists reported by others $(4,6)$. Atropine-binding was inhibited by low concentrations 
of muscarinic antagonists but not by nicotinic antagonists. In contrast, ACh-binding was strongly inhibited by low concentrations of atropine and oxotremorine. The $K_{D}$ values of the two ligands obtained in the present study were comparable with the potencies of their peripheral muscarinic actions $(14,15)$. It seems reasonable to assume that the muscarinic receptors in the central nervous system should have similar properties to those of receptors in the peripheral nervous system. Thus, we suggest that the bindings of the two ligands examined in the present study are bindings to muscarinic receptors. Moreover, under our conditions ACh-binding to nicotinic receptors is probably negligible since it has been reported that there are only one tenth as many nicotinic as muscarinic receptors in the brain (16), and because in the peripheral nervous system, $\mathrm{ACh}$ is known to have a lower affinity for nicotinic receptors than for muscarinic receptors. It is difficult to consider that the part of ACh-binding which was not inhibited by atropine was nicotinic because oxotremorine which had no nicotinic action on frog striated muscle at the concentration to $10^{-4} \mathrm{M}$ (not shown) inhibited ACh-binding perfectly (Fig. 3B, Fig. 7) (15). Schleifer and Eldefrawi (5), in their study of the bindings of atropine and $\mathrm{ACh}$ to mouse brain measured by equilibrium dialysis, reported that the binding site to ACh was much less than that to atropine. The discrepancy between these results may be duc to the long incubation ( $36 \mathrm{hr}$ ) for equilibrium dialysis used in their study.

Synaptic plasna membrane fractions are mainly composed of presynaptic and junctional postsynaptic membranes (17). Thus some of the postsynaptic receptors may not be recovered in this fraction and the muscarinic receptors present may be mainly presynaptic receptors. However, these muscarinic receptors seemed to be uniform in nature. Birdsall and Hulme proposed, from experiments on the inhibition of antagonist-binding by $\mathrm{ACh}$, that there are two kinds of ACh-binding sites in the brain which have different affinities (13). Their suggestion that there are two different types of muscarinic receptors is not consistent with our observation that ACh-binding has a single high affinity and that it is proportional to the amount of atropine-binding. Further detailed quantitative studies should clarify this problem.

On nicotinic receptors, $\mathrm{Ca}^{++}$competes with agonists both in vivo and in vitro $(18,19)$. Muscarinic actions may be mediated by increase in permeability of the membranes to $\mathrm{Ca}^{++}$ (20). However, we found that removal of $\mathrm{Ca}^{++}$from the medium had no affect on atropinebinding or on the inhibitory effect of ACh on atropine-binding.

Simantov and Snyder reported that monovalent cations have strong influences on an opiate receptor (21). We found that replacentent of $\mathrm{Na}^{+}$in the medium by $\mathrm{K}^{+}$or $\mathrm{Li}^{+}$had no significant affect on the muscarinic receptors.

The membrane fraction contained fewer ACh-binding sites than atropine binding sites, but on preincubation with DTNB, the number of binding sites for $\mathrm{ACh}$ and for atropine became equal. Nicotinic receptors are known to contain a disulfide bond which plays an important role in the activity of these receptors (22). Moreover, DTT and DTNB are known to cause breakdown and formation of disulfide bonds, respectively. Thus the receptors which are oxidized by DTNB may contain a disulfide bond in the physiological state, but 
during homogenization, disulfide bonds on the outer surface of plasma membranes may be reduced by thiol compounds in the intracellular fluid. However, we failed to mimic these effects using other disulfide compounds such as cystamine and cystine. Moreover, the possibility that the half to the DTNB molecule is bound to the thiol groups of the receptors and that it has this pharmacological effect remains to be tested (23). Nevertheless, in either case a thiol or disulfide group in the receptor plays an important role on the state of ACh-binding site.

Unlike ACh-binding, atropine-binding was not affected by DTNB. However, the inhibitory effect of $\mathrm{ACh}$ on atropine-binding was increased by pretreatment of the membranes with DTNB. It seems unlikely that the increases in ACh-binding and the inhibitory effect of ACh on atropine-binding are both due to a single effect on one site, because a high concentration of $\mathrm{ACh}$ was required to inhibit the binding of atropine, although $\mathrm{ACh}$ itself has high binding affinity. Thus the two actions of ACh may be due to the binding of ACh to different sites (Fig. 6, Table 1).

Ariëns and Beld (18) suggested that many kinds of receptors may have two different sites for binding of an agonist and an antagonist and that muscarinic receptors also seem to have these two binding sites. Our data on the differences in sensitivities of the two bindings to DTNB and on the differences of the potencies of agonists and antagonists which inhibit the bindings of the other type of ligand support their suggestion.

Snyder et al. demonstrated that the binding of the antagonist, quinuclidinyl benzilate, to receptors is strongly inhibited by antagonists but weakly inhibited by agonists (4). Our data on atropine-binding are consistent with theirs. However, we did not observe the reverse relation that the binding of the agonist was weakly inhibited by the antagonists. That is, the potency of atropine in inhibiting the binding of $\mathrm{ACh}$ was equal to its peripheral pharmacological actions. Fig. 9 shows the binding of both atropine and $\mathrm{ACh}$ in the presence of $2 \times 10^{-9} \mathrm{M}$ atropine and various concentrations of $\mathrm{ACh}$ with $1 \mathrm{mM}$ DTNB. Values for atropine-binding are from Fig. 5 and those for ACh-binding were calculated from the $K_{D}$ value of $\mathrm{ACh}\left(2 \times 10^{-8} \mathrm{M}\right)$ and the $\mathrm{K}_{\mathrm{I}}$ value of atropine $\left(4 \times 10^{-9} \mathrm{M}\right)$ for ACh-binding. Vertical axis indicates the percent of maximal binding of both ligands. For instance, in the presence of $\mathrm{ACh}\left(5 \times 10^{-9} \mathrm{M}\right)$ and atropine $\left(2 \times 10^{-9} \mathrm{M}\right)$, the sum of the two bindings is more than $100 \%$. These facts suggest that there are two different binding sites on one receptor,

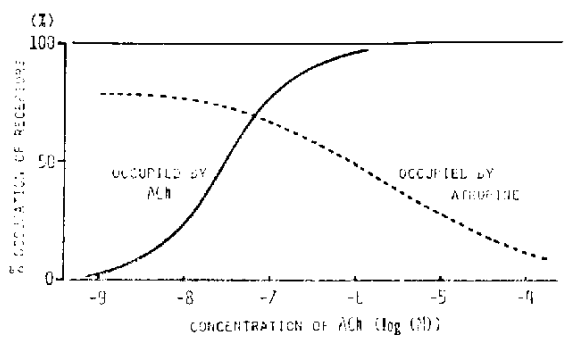

Fig. 9. Bindings of $\mathrm{ACh}$ and atropine to synaptic plasma membranes (preincubated with DTNB) in the presence of $2 \times 10^{9} \mathrm{M}$ atropine plus various concentrations of $\mathrm{ACh} . \quad 100 \%$ corresponds to $1.5 \div 10^{-12} \mathrm{moles} / \mathrm{mg}$ prot. for both bindings. 
and that a receptor can be bound both by ACh and atropine at the same time. Under these conditions the potencies of the peripheral actions of ACh and atropine suggest that AChbinding may have the dominant effect of changing the configuration of the receptors.

Acknowledgement: This work was partly supported by a grant for scientific research from the Ministry of Education, Science and Culture, Japan.

\section{REFERENCES}

1) Salmotraght, G.C. nnd Stefanis, C.N.: A critique of iontophoretic studies of central nervous system neurons. Int. Rev. Neurobiol. 10, 1-30 (1967)

2) BRAdlex, P.B.: Synaptic transmission in the central nervous system and its relevance for drug action. Int. Rev. Neurobiol. 11, 1-56 (1968)

3) Dingledinf, R. ANd Kelly, J.S.: Brain stem stimulation and the acetylcholine-evoked inhibition of neurones in the feline nucleus reticularis thalami. J. Physiol. 271, 135154 (1977)

4) Snyder, S.H., Chang, K.J., Kuhar, M.J. and Yamamura, H.I.: Biochemical identification of the mammalian muscarinic cholinergic receptor. Fedn Proc. Am. Soc. exp. Biol. 34, 1915-1921 (1975)

5) Schleifer, L.S. AND Eldefrawi, M.E.: Identification of nicotinic and muscarinic acetylcholine receptors in subcellular fractions of mouse brain. Neuropharmacology 13, 53-63 (1974)

6) Farrow, J.T. AND O'BrIEN, R.D.: Binding of atropine and muscarone to rat brain fractions and its relation to the acetylcholine receptor. Mol. Pharmacol. 9, 33-40 (1973)

7) Hadhazy, P. ANd SzERB, J.C.: The effect of cholinergic drugs on $\left[{ }^{3} \mathrm{H}\right]$-acetylcholine release from slices of hippocampus, striatum and cortex. Brain Res. 123, 311-322 (1977)

8) Ariïns, E.J. AND Bfld, A.J.: The receptor concept in evolution. Biochem. Pharmacol. 26, 913-918 (1977)

9) Rosen, G.M., Rauckman, E.J. and Abou-Donia, M.B.: The question of cholinergic antagonism. Biochem. Pharmacol. 25, 2761-2764 (1976)

10) Whittaker, V.P., Michaelson, I.A. and Kirkland, R.J.A.: The separation of synaptic vesicles from nerve-ending particles ('Synaptosomes'). Biochem. J. 90, 293-305 (1964)

11) SAITO, K., UChida, S. AND YosHIDA, $\mathrm{H}$.: Calcium binding of isolated synaptic membranes from rat cerebral cortex. Japan. J. Pharmacol. 22, 787-798 (1972)

12) Nordberg, A. AND Sundwall, A.: Biosynthesis of acetylcholine in different brain regions in vivo following alternative methods of sacrifice by micro wave irradiation. Acta physiol. scand. 98, 307-317 (1976)

13) Birdsal., N.J.M. and Hulme, H.C.: Biochemical studies on muscarinic acetylcholine receptors. J. Neurochem. 27, 7-16(1976)

14) Triggle, D.J.: Neurotransmitter-Receptor Interactions, Chapter IV, p. 209 - 400, Academic Press, London and New York (1971)

15) Cho, A.K., Haskett, W.L. A.ND Jenden D.J.: Peripheral actions of oxotremorine, a metabolite of tremorine. J. Pharmacol. exp. Ther. 138, 249-257 (1972)

16) Salvaterra, P.M., Mahler, H.R. and Moore, W.J.: Subcellular and biochemical distribution of ${ }^{125} \mathrm{I}-1 \mathrm{abeled}-\mathrm{b} u n g a r o t o x i n$ binding in rat brain and its relationship to acetylcholinesterase and choline acetyltransferase. J. biol. Chem. 250, 6469-6475 (1975)

17) De Robertis, E. and Rodriguez de Loves Arnaiz, G.: Handbook of Neurochemistry, Edited by LAJTHA, A., Vol. 2, p. 365-392 (1969)

18) TAYLOR, D.B.: The role of inorganic ions in ion exchange processes at the cholinergic receptor of voluntary muscle. J. Pharmacol. exp. Ther. 186, 537-551 (1973)

19) Martinez-Carrion, M. and Raftery, M.A.: Use of fluorescent probe for the study of ligand binding by the isolated cholinergic receptor of Torpedo californica, Biochem. biophys. Res. Commun. 55, 1156-1164 (1973)

20) Rasmussen, H.: Cell Membrane, Edited by Weissman, G. and Claiborne, R., p. 203-2I2, 
HP Publishing Co., New York (1975)

21) Simantov, R. and Snyder, S.H.: Morphine-like peptides, lcucine enkephalin and methionine enkephalin: Interaction with opiate receptor. Mol. Pharmacol. 12, 987-998 (1976)

22) Karlin, A. AND Bartels, E.: Effects of blocking sulfhydryl group of reducing disulfide bonds on the acctylcholine-activated permeability system of the electroplax. Biochim. Biophys. Acta 126, 525 535 (1966)

23) Barthis-Bernal, E., Rosinberky, T.J. and Chang. H.W.: A membrane activation cycle induced by sulfhydryl reagents after affinity labeling of the acetylcholine receptor of clectroplax. Mol. Pharmacol. 12, 813-819 (1976) 